\title{
Nucleolysin TIA-1 Isoform p40
}

National Cancer Institute

\section{Source}

National Cancer Institute. Nucleolysin TIA-1 Isoform p40. NCI Thesaurus. Code C127899.

Nucleolysin TIA-1 isoform p40 (386 aa, 43 kDa) is encoded by the human TIA1 gene. This protein is involved in RNA binding, alternative splicing, translational regulation and nucleolysis. 